\title{
A interação entre crianças surdas no contexto de uma escola de Educação Infantil
}

\author{
Carolina Oliveira Jimenez Silvestre* \\ Erica Aparecida Garrutti de Lourenço**
}

\begin{abstract}
Resumo
Este artigo objetiva conhecer como se dá interação entre crianças surdas na Educação Infantil. A metodologia pautou-se na observação em campo de uma turma de Educação Infantil em uma escola especializada na Educação de Surdos da Rede Municipal de São Paulo. Foram realizadas também entrevistas com a professora da turma observada e a coordenadora. Como outros procedimentos de coleta de dados, analisou-se o Projeto Político Pedagógico da escola e realizou-se uma atividade dirigida com as crianças. Os resultados revelaram que as interações entre as crianças surdas ocorrem naturalmente, visto que essas crianças compartilham de uma mesma língua, a Língua de Sinais e da mesma cultura. A escola pesquisada tem como meta respeitar a língua, a cultura e a identidade surda, tendo a preocupação em centrar-se no uso da LIBRAS como forma de comunicação para o favorecimento da aprendizagem da criança surda.
\end{abstract}

Palavras-chave: Educação de surdos; Interação entre crianças; Educação Infantil; Bilinguismo.

\footnotetext{
* Estudante do Curso de Pedagogia, da Universidade Federal de São Paulo (Unifesp). São Paulo, São Paulo.

** Professora do Curso de Pedagogia, da Universidade Federal de São Paulo (Unifesp), São Paulo, São Paulo.
}

Revista Educação Especial | v. 26 | n. 45, | p. 161-174 | jan./abr. 2013

Santa Maria

Disponível em: <http://www.ufsm.br/revistaeducacaoespecial> 


\title{
The interaction between deaf children in the context of an early childhood education School
}

\begin{abstract}
This paper's objective is to understand how deaf children interact in Childhood Education. The methodology was based on field observation of a group of young children being taught in a Sao Paulo Public School that specializes in the education of deaf people. Interviews were also carried-out with the teacher of the observed class and the school coordinator. As in other datacollection procedures, we analyzed the school's pedagogical-political project and conducted a guided activity with the children. Results revealed that interactions among deaf children occur naturally, since these children share the same language (sign language) and culture. The researched school aims to achieve respect of the deaf language, culture and identity, focusing on the use of LIBRAS (Brazilian Sign Language) as a means of communication favoring the learning process of deaf children.
\end{abstract}

Keywords: Education of deaf people; Interaction among children; Childhood Education; Bilingualism.

\section{Introdução}

A Educação dos Surdos tem apresentado avanços continuamente, com a luta da comunidade surda e de estudiosos que almejam uma educação que atenda todos os cidadãos, permeada pelo respeito às diferenças. Quando se trata da interação das crianças surdas, a comunicação entre pares e demais integrantes da sociedade é assunto emergente, pois favorece a interação, o que ocorre com qualquer ser humano.

Segundo Vygotsky (2007), é a partir das relações sociais que o homem se constitui, ou seja, ele se forma mediante a interação com os outros e essa é mediada pela linguagem. É por meio dos processos interativos que o aprendizado flui com maior facilidade e a criança surda se desenvolve em todos os âmbitos como o psicológico, o emocional, o cognitivo e o social. As crianças surdas, assim como as ouvintes, aprendem por meio do brincar, das curiosidades, do contato social, com a família; a aprendizagem também depende da interação delas com o meio e com as pessoas. Nesse sentido, também Góes (p. 37, 2002) afirma que "o desenvolvimento da criança surda deve ser compreendido como processo social, e suas experiências de linguagem concebidas como instâncias de significação e de mediação nas suas relações com a cultura, nas interações com o outro". Corroborando com a ideia, Gesueli destaca que: 
A linguagem terá um papel fundamental, como mediadora das interações e da significação do mundo, ou ainda, a concepção de que o sujeito não significa o mundo para, a partir de então, representá-lo pela linguagem, mas, sim, que essa significação se constrói também pela própria linguagem. (GESUELI, 2006, p. 280)

A aquisição da linguagem pela criança surda ocorre da mesma maneira com crianças ouvintes, porém os ouvintes utilizam da linguagem oral-auditiva e os surdos, a linguagem visual-espacial. A língua adquirida naturalmente pelas crianças surdas é a Língua de Sinais pelo fato de não ouvirem. Duas grandes estudiosas a respeito da aquisição da Língua de Sinais, Quadros e Karnopp (2004), afirmam que a Língua Brasileira de Sinais (LIBRAS) é uma língua natural para os surdos e que possui características próprias, portanto um caráter específico, assim como qualquer outra língua oral-auditiva.

Quanto à aquisição da Língua de Sinais, na maioria das vezes, ocorre de forma tardia, pois os surdos, em maioria, são filhos de pais ouvintes (95\%, aproximadamente). Uma vez que os pais não têm contato com essa língua, se torna mais difícil a aquisição da linguagem favorecida pelas dimensões visual e espacial para a criança surda. Desse modo, ela terá frequentemente problemas sociais, emocionais e cognitivos como consequência (GOLDFELD, 2002).

A criança surda, principalmente, filha de pais ouvintes, deve ser integrada à comunidade surda desde muito cedo para que tenha contato e realize trocas sociais com pares surdos, podendo ter um desenvolvimento que propicie uma capacidade de aprendizagem como a de uma criança ouvinte. Se imersa desde pequena na comunidade surda, essa criança adquire sua língua materna de forma natural e se integrará também à comunidade e cultura ouvinte, sem, é claro, deixar as suas próprias características da cultura e comunidade surda.

Tendo em vista a relevância das condições sociais para o desenvolvimento da criança surda, este estudo volta-se para o conhecimento de particularidades da interação de crianças surdas matriculadas em uma escola especializada na Educação de Surdos. Nesse sentido, constitui seu objetivo: investigar como se dá a interação de crianças surdas em uma instituição de Educação Infantil, por meio da observação das atividades realizadas com a mediação de educadores bilíngues ou não, surdos ou ouvintes. 


\section{Procedimentos Metodológicos}

A escola pesquisada é uma escola bilíngue para surdos, da rede municipal de São Paulo. Para matrícula na escola, tem-se como pré-requisito que a criança seja surda. A instituição atende todos os ciclos desde a Educação Infantil até o Ensino Médio e, ainda, o EJA (Educação de Jovens e Adultos). Dessa escola, constituíram participantes deste estudo: um coordenador pedagógico, um professor de uma turma de Educação Infantil, em uma escola pública especializada na Educação de Surdos, e sete crianças surdas com faixa etária que varia entre três e seis anos de idade.

Inicialmente, a escola foi contatada, solicitando-se a autorização para a realização da pesquisa, esclarecendo-se fundamentalmente que como procedimentos éticos a identidade dos participantes e da escola seria preservada.

Em seguida, iniciou-se a coleta de dados, viabilizada pelo uso de três instrumentos: roteiros de entrevistas semi-estruturadas direcionadas ao coordenador pedagógico da escola e ao professor, observação da rotina de um grupo de crianças surdas da Educação Infantil, desenvolvimento de uma atividade dirigida por uma das pesquisadoras deste estudo com as crianças e roteiro para a análise do Projeto Político Pedagógico da escola.

As entrevistas foram formadas por questões que enfatizavam o conhecimento de aspectos concernentes à interação social das crianças na Educação Infantil. A aplicação de cada entrevista durou um tempo estimado de 15 a 30 minutos, que dependeu da disponibilidade de cada entrevistado. No início de cada entrevista, foi solicitada autorização para a gravação das falas para, posteriormente, transcrevê-las e realizar uma análise qualitativa dos dados obtidos. Esse procedimento de coleta dados é considerado de suma importância, pois são as pessoas que convivem diariamente com as crianças surdas e que fazem parte do seu processo de escolarização, apresentando diferentes propostas para que as crianças surdas na Educação Infantil alcancem o esperado desenvolvimento pleno, que só ocorre quando as mesmas interagem de forma natural e positiva com a sociedade.

A observação de um grupo da Educação Infantil ocorreu em quatro dias seguidos, sem interrupção, no período vespertino, desde o início das atividades do grupo até o término do intervalo. A observação buscou conhecer como é desenvolvida a rotina das crianças nas atividades propostas e nos momentos do brincar, verificando as interações correntes nesses momentos específicos. Os episódios interativos foram registrados em um diário de campo. 
A atividade dirigida consistiu na contação em LIBRAS da história "Os Três Porquinhos". Essa história era apresentada em um livro que foi adaptado especificamente para essa contação, formado por imagens em relevo e por fotos que apresentavam os principais sinais da história. Após a contação, as crianças manusearam o livro e recontaram a história, sendo que cada uma contou um trecho (uma página) do livro.

O projeto político pedagógico da escola foi analisado, registrandose os pressupostos e as ações que favoreceriam a interação das crianças surdas no contexto da escola.

\section{Resultados e Discussão}

O desenvolvimento de crianças surdas na Educação Infantil não é diferente do desenvolvimento de uma criança ouvinte, também é através de processos de interação que o aprendizado acontece com mais facilidade, desenvolvendo o indivíduo surdo em todos os âmbitos como psicológico, emocional, cognitivo e social. Diante de uma perspectiva histórico-cultural, o desenvolvimento da criança surda deve ser entendido como um processo social, levando em conta suas experiências, sua cultura e suas relações de interação com o outro (GÓES, 2002). O que realmente altera-se é a questão da comunicação, da Língua de Sinais usada como primeira língua. Nesse sentido, vale ressaltar que

O ato de comunicar-se é troca, é interação e pode tornarse um jogo interessante, se respeitadas as diferenças. Os alunos surdos possuem linguagem interna muito rica, possuem graus variados de informações que o saber formal tem potencial para expandir, e o reconhecimento desta potencialidade é fundamental para a escolaridade. (NIENDICKER; ZYCH, 2008, p. 5)

Ou seja, se o que difere o desenvolvimento de uma criança surda para uma criança ouvinte é a forma comunicativa, esse não é o problema visto que as interações acontecerão naturalmente entre as crianças surdas, pois é usada a Língua de Sinais. Como afirmado nessa citação, o surdo tem seu potencial, basta o docente saber como desenvolvê-lo, considerando as experiências, as informações por ele trazidas e principalmente respeitar a sua língua e cultura surda.

A seguir, serão relatados alguns episódios observados que caracterizam as relações interpessoais entre as crianças surdas em atividades, brincadeiras e outros momentos. O primeiro episódio se refere a uma atividade rotineira, a chamada realizada todos os dias, antes de qualquer 
outra atividade. A chamada é feita da seguinte maneira: a professora pega placas com os nomes das crianças e pede a elas que identifiquem quem ela está chamando. Após a identificação do nome, as crianças fazem o sinal da criança chamada e colocam a placa no mural escola para as crianças que estão presentes ou casa para as crianças que não estão presentes.

Esse primeiro episódio refere-se à interação entre duas crianças, as quais estão participando da atividade de chamada:

A professora Janaina mostra a placa com o nome do Pedro e pergunta em LIBRAS para Ricardo quem é a criança que tem aquele nome. Ricardo apenas olha a placa e não responde. A professora pergunta novamente, então, Ricardo pega a placa e vai até a foto de Pedro e mostra quem é a criança. Em seguida, a professora pergunta em LIBRAS qual o sinal de Pedro e Ricardo responde sem dificuldades. Quando é questionado se Pedro está na escola ou em casa, Ricardo novamente não responde. Lilia interrompe Ricardo e a professora para ajudar seu colega. Lilia mostra ao amigo que Pedro está na escola, que não tinha faltado. Sinaliza em LIBRAS: PEDRO (sinal pessoal) - AQUI - ESCOLA. Em seguida, Ricardo concorda com Lilia e coloca a placa do nome de Pedro no mural da escola. (Relato do diário de campo)

Esse momento de interação entre as duas crianças surdas exemplifica como uma criança coopera com a outra em situações de dificuldades de uma forma muito natural e desenvolta. Essa naturalidade acontece porque estão entre pares, partilhando de uma mesma língua em uma escola especializada na Educação de Surdos, ou seja, nesse espaço as crianças surdas se comunicam, se ajudam, brincam, interagem e se desenvolvem conforme as oportunidades que lhes são oferecidas na escola.

Segundo Lopes (in SLKLIAR, 2010), as trocas culturais dos surdos que compartilham de uma mesma língua, auxiliam no processo escolar, na organização dos movimentos surdos, na convivência e na formação de comunidades surdas, ou seja, a escola de surdos, aceita, reconhece e valoriza essa comunidade, cultura e identidade surda e as características que formam esses meios culturais.

Outro momento interativo ocorreu com três crianças durante a realização de uma atividade que se baseava na medição da altura das crianças. A professora pegou um rolo de papel pardo e mediu cada criança. No decorrer dessa atividade, Lilia, Ricardo e Jaqueline comparavam suas alturas para saber quem era mais alto ou mais baixo. 
Lilia sinalizou em LIBRAS: EU-ALTA. Jaqueline responde logo em seguida EU - TAMBÉM. Lilia e Jaqueline ficam lado a lado e se medem e as duas percebem a diferença na altura. Jaqueline reconhece que Lilia é mais alta e diz VOCÊ - ALTA. Ricardo observa esse momento em que as crianças se comparavam e resolveu participar. Ricardo diz em LIBRAS: EU. Lilia vai ao seu lado e mede quem é mais alto e, para sua decepção, Ricardo é mais alto. Ricardo diz repetitivamente: EU - ALTO - ALTO. Lilia simplesmente o deixa sozinho por não ser mais alta que ele. (Relato do diário de campo)

Nesse episódio, observa-se a facilidade na comunicação entre as crianças surdas, pois como dito anteriormente, compartilham de uma mesma língua. O contato da criança surda com outra pessoa surda, seja ela outra criança ou adulto, terá sempre um reflexo positivo, pois favorecerá a constituição de uma identidade surda que, segundo os pensamentos de Perlin (2003), revela o jeito surdo de ser, de sentir, de vivenciar, de perceber, de comunicar e de transformar o mundo.

Esse é um dos objetivos da escola, quando o Projeto Político Pedagógico destaca a importância de se proporcionar uma comunicação natural através de interlocutores surdos ou ouvintes fluentes em LIBRAS:

O objetivo da escola está pautado numa proposta Bilíngue como sistema de educação para surdos, pressupõe o ensino de duas línguas para a criança. A primeira é a LIBRAS, que lhe dará o arcabouço para a aprendizagem de outra língua e a segunda língua é a Língua Portuguesa escrita. Isto significa que a criança é exposta à LIBRAS por meio de interlocutores surdos ou ouvintes que tenham proficiência na LIBRAS. (Projeto Político Pedagógico da Escola)

$\mathrm{Na}$ escola, além de se propiciar o contato direto entre as crianças surdas, não há a necessidade da presença do intérprete, pois há o contato direto com a cultura, valores e principalmente com a Língua de Sinais. Desse modo, com uma comunicação eficaz entre os pares, a criança alcançará o desenvolvimento pleno como qualquer outra criança imersa na rede regular de ensino (LOPES in SKLIAR, 2010).

A professora da turma observada, Janaina, destaca aspectos relevantes no que diz respeito à comunicação entre as crianças surdas na Educação Infantil 
A criança surda quando chega à escola, essa criança pequena de três, quatro anos, eles não tem absolutamente nada em comunicação, então eles chegam e a comunicação deles é bater, chorar, brigar, porque eles não têm como se expressar. A partir do momento que eles estão interagindo em grupo e com a professora numa escola onde todos tem a mesma língua, que seria a língua de sinais, eles começam a ter um contato com a língua própria do surdo, que é a língua de sinais [...]. (Informação verbal da entrevista, 2012)

\title{
Em outro momento da entrevista, a professora relata ainda que
}

\begin{abstract}
É muito importante a criança ter referência de outra criança parecida com ela, então, ela bate, ela morde, como toda criança, a surda também tem a fase egocêntrica, quer tudo para ela. Então, tudo isso é um monte de estímulos que a criança está recebendo e, aos poucos, ela vai estruturando na medida em que ela vai adquirindo a língua de sinais. (Informação verbal da entrevista, 2012)
\end{abstract}

Com esses relatos da professora, é possível reafirmar o que se dizia anteriormente, quando a criança surda adquire sua língua natural, a Língua de Sinais, logo consegue se comunicar com outras crianças surdas e é notável e importantíssimo o contato com outras crianças surdas, pois assim essa criança percebe que é igual às outras em termos de comunicação, claro cada uma com suas diferenças e suas singularidades, assim como todas as pessoas surdas ou ouvintes.

Quando a professora afirma que as crianças surdas batem, mordem, enfim, faz referência ao fato de que apresentam ações que, muitas vezes, são interpretadas como sinais de agressividade em conformidade com o mito de que as crianças surdas são mais agressivas. Mas, na verdade, elas passam pelas mesmas fases que as crianças ouvintes, requerem que intervenções contínuas sejam feitas no sentido de que compreendam o sentido de suas ações no coletivo.

De modo semelhante, a coordenadora expõe que

Para a criança surda, é importante que ela esteja na Educação Infantil, porque o contato com outra criança surda favorece na aquisição da língua. Como a criança pequenininha vem para escola sem essa língua, a escola vai acabar dando essa base, essa oportunidade que, em casa, geralmente eles não têm, porque a maioria dos nossos alunos são filhos de pais ouvintes, então, é 
fundamental que a criança surda esteja o quanto antes na escola [...]. (Informação verbal da entrevista, 2012)

Nessa fala, destaca-se a importância da aquisição da Língua de Sinais precocemente, pois, se a criança surda é matriculada o mais cedo possível em uma instituição de educação, ela interagirá com outras pessoas e, mais rápido, adquirirá a sua língua natural, se essa instituição for uma instituição bilíngue. Corroborando com ideia da aquisição precoce da LIBRAS, evitando o atraso de linguagem, Goldfeld (2002, p. 58), coloca que

[...] a linguagem além de ter a função comunicativa exerce também as funções organizadora e planejadora, ou seja, é instrumento do pensamento mais importante que o homem possui, percebe-se o quanto a criança surda que sofre atraso de linguagem fica em desvantagem em relação às crianças que adquirem a linguagem naturalmente.

Ou seja, se a criança não tem a LIBRAS e não está imersa em uma escola de educação bilíngue, ainda mais sendo filha de pais ouvintes, terá um atraso de linguagem significativo que poderá causar danos e comprometer o seu desenvolvimento. Assim, a melhor forma de a criança surda adquirir sua língua natural é ingressando em uma instituição bilíngue, seja especializada ou da rede regular de ensino, desde que tenha o contato com outras crianças surdas ou adultos surdos.

Para que uma escola bilíngue de rede regular de ensino respeite às particularidades do surdo, faz-se necessário o cumprimento do Decreto 5626/2005. Esse documento em relação à educação da criança surda, destaca a necessidade de prover escolas com professor de Libras ou instrutor de Libras, tradutor e intérprete de Libras - Língua Portuguesa, professor para o ensino de Língua Portuguesa como segunda língua para pessoas surdas e professor regente de classe com conhecimento acerca da singularidade linguística manifestada pelos alunos surdos. Ainda, prevê e garante que a criança surda tenha o contato com outro surdo ou um intérprete. Porém, o ideal para a construção da identidade da criança surda é que esse adulto imerso na instituição seja surdo.

E, ainda, o documento do Ministério da Educação, relacionado às questões de educação inclusiva de surdos, "Educação Infantil: Saberes e práticas da inclusão", coloca como condição para as escolas de ensino regular que realizam inclusão de crianças surdas: 
É fundamental que a equipe escolar estabeleça a metodologia a ser utilizada para desenvolver a comunicação e a linguagem da criança. É preciso verificar em que fases do desenvolvimento elas se encontram e quais etapas ainda não alcançaram, como por exemplo o brincar com o próprio corpo e, ao mesmo tempo, com a própria voz; o usar da comunicação corporal e gestual, a atividade exploratória, o jogo simbólico (BRASIL, 2006, p. 46)

Ou seja, a inclusão de surdos em instituições de ensino regular pode ocorrer com eficiência desde que respeitados os aspectos da cultura e comunidade surda, além de contemplar todas as possíveis necessidades dessas crianças para que as mesmas sintam-se parte integrante do meio no qual estão inseridas, na escola.

Será exposto outro registro do diário de campo que trata de um episódio de interação entre as crianças em um momento de brincadeira.

Após a realização de uma atividade, a professora deixou que brincassem livremente na sala de aula. Lilia, Leandro e Gustavo começaram a brincadeira de "Polícia e Ladrão". Leandro sinalizou em LIBRAS para as crianças: POLÍCIA - EU - ELE. As crianças começaram a correr de Leandro, que simulou ter uma arma de fogo. Depois de correr bastante, Lilia se cansou e sinalizou para os colegas: PARAR - CANSADA. Os três sentam para descansar. Durante esse momento, Ricardo que brincava com Jaqueline com os brinquedos disponíveis na sala, empurra Gustavo, que chora. Em seguida, Ricardo pede desculpas ao amigo. Gustavo pára de chorar e responde em LIBRAS: BEM. Voltam a correr e Leandro continua sendo o policial, com sua arma de fogo, imita sons de tiro. (Relato do diário de campo)

Esse momento de interação desperta atenção pelo fato de uma criança surda imersa em uma escola de surdos produzir sons, o que é natural para os ouvintes. Essa criança por ser filha de pais ouvintes, de certa forma, é participante da cultura e da comunidade ouvinte, assim ela interioriza algumas características da sua realidade na brincadeira. Silva (2002) corrobora com essa ideia quando menciona que a cultura ouvinte constitui o surdo e torna ele parte integrante de sua subjetividade, das diferenças linguísticas. Nesse sentido, nada se perde, pois não há uma cultura que se sobreponha à outra, mas uma dinâmica entre os homens, caracterizada pela troca. A diversidade é vista como elemento fundamental para a constituição da singularidade. 
Será exposto um último episódio que ilustra a relação de interação entre as crianças surdas da turma observada na atividade dirigida por uma das autoras deste estudo de contação e recontação de uma história infantil "Os Três Porquinhos". Segue a descrição do episódio de como as crianças recontaram a história:

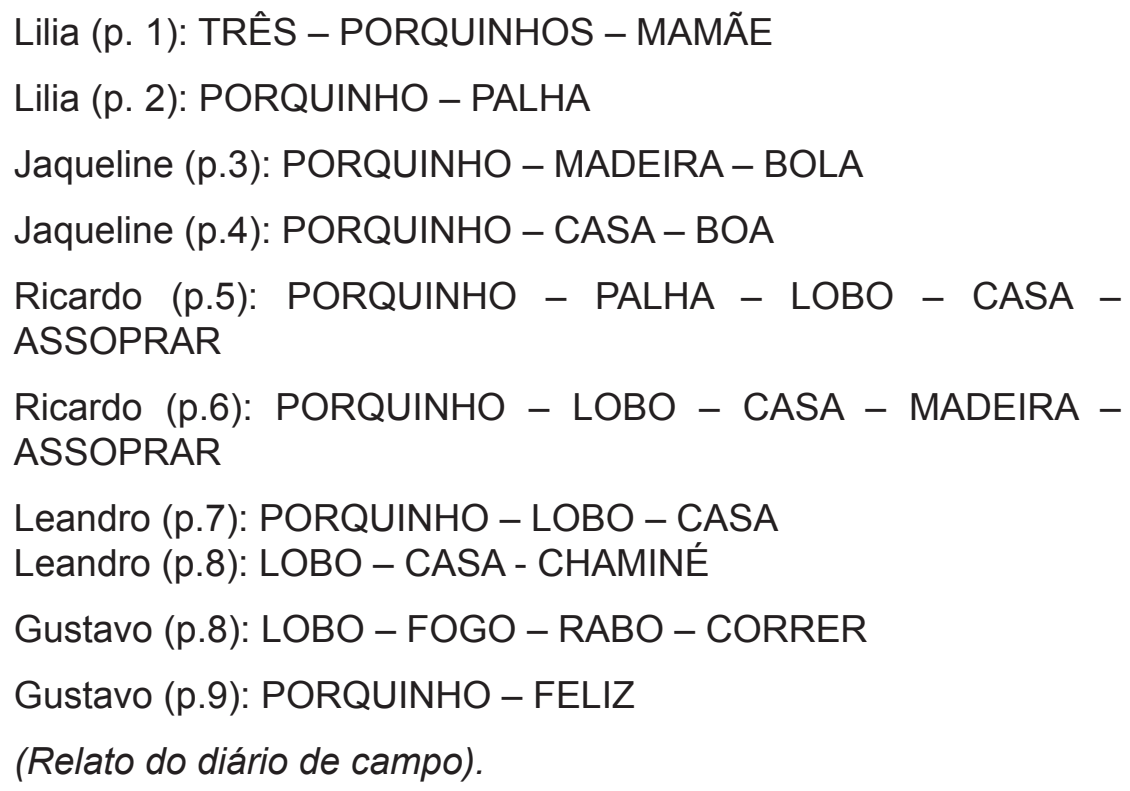

Nesse momento, nota-se que as crianças observavam atentamente como os colegas contavam a história e recontaram de forma que fizesse sentido para elas mesmas. Elas compreenderam o que os colegas diziam, sem grandes dificuldades. Em alguns sinais, como CHAMINÉ, a professora as auxiliava na realização, mas, em geral, foi perceptível a compreensão da história pelas crianças por meio da contação em Língua de Sinais. As crianças se comunicavam, riam, divertiam-se e, principalmente, essa atividade teve sentido para elas, pois o livro era formado por imagens coloridas e em alto relevo e por um glossário com fotos dos sinais das principais palavras. Perceberam que aquele material foi feito para crianças como elas e adoraram recontar a história para a turma. Vale destacar que esse foi um momento relevante visto que as crianças deram orientação à atividade, recontaram na língua delas e para elas.

Por fim, destaca-se a importância dos processos interativos entre as crianças surdas pela linguagem e pela brincadeira, pois, quando trocam sinais, corrigem uns aos outros, se ajudam e aprendem juntas. O contato da 
criança surda imersa em um ambiente com seus pares traz apenas benefícios e reflexos positivos ao seu desenvolvimento físico, mental, social, intelectual, entre outros tantos aspectos que se almejam para que a criança surda se torne um cidadão crítico, reflexivo e plenamente desenvolvido, com suas capacidades e necessidades contempladas, se tornando uma pessoa surda com cultura e identidade própria, respeitada e valorizada.

\section{Considerações finais}

A escola pesquisada atende as necessidades interativas das crianças surdas na Educação Infantil. Esclarece-se no Projeto Político Pedagógico que a escola pauta-se no bilinguismo para o desenvolvimento de suas ações. Nesse sentido, os funcionários, em geral, têm o domínio básico da LIBRAS.

No que diz respeito aos processos de interação, as relações interpessoais acontecem naturalmente, visto que são crianças e sentem a necessidade de se interagirem e, principalmente, por compartilharem de uma mesma língua, de uma mesma cultura e de uma mesma comunidade. As interações viabilizadas pela comunicação fluem prazerosamente, pois as crianças imersas na instituição compartilham de uma mesma língua, a LIBRAS e, desse modo, conseguem ter uma comunicação eficaz, consequentemente tendo um desenvolvimento cognitivo, emocional, mental, físico, enfim alcançando o desenvolvimento pleno.

\section{Referências}

BISOL, C.; SPERB, T. M. Discursos sobre a surdez: deficiência, diferença, singularidade e construção de sentido. Psicologia: teoria e pesquisa, Rio Grande do Sul. v. 26, n. 1, p. 7-13, jan./mar. 2010. Disponível em: <http://www. lume.ufrgs.br/bitstream/handle/10183/28990/000748862. pdf? sequence=1> Acesso em: 19 abr. 2012.

BRASIL. Decreto $\mathbf{N}^{\circ} \mathbf{5 . 6 2 6}$, de 22 de dezembro de 2005. Regulamenta a Lei no 10.436, de 24 de abril de 2002, que dispõe sobre a Língua Brasileira de Sinais - Libras, e o art. 18 da Lei no 10.098, de 19 de dezembro de 2000. Brasília. 2005. Disponível em: < http://www.planalto.gov.br/ccivil_03/_ Ato2004-2006/2005/Decreto/D5626.htm> Acesso em: 22 out. 2011.

Secretaria de Educação Especial. Educação infantil: saberes e práticas da inclusão: dificuldades de comunicação e sinalização: surdez. 4. ed. Daisy Maria Collet de Araujo Lima - Secretaria de Estado da Educação do Distrito Federal. Brasília: MEC, 2006. 89 p. 
GESUELI, M. Z. Lingua(gem) e identidade: a surdez em questão. Educ. Soc., Campinas, v. 27, n. 94, p. 277-292, jan./abr. 2006. Disponível em: <http://www.cedes.unicamp.br> Acesso em: 09 out. 2011.

GÓES, M. C. R. de. Linguagem, surdez e Educação. Campinas: Autores Associados, 2002. $97 \mathrm{p}$.

GOLDFELD, M. A criança surda: linguagem e cognição numa perspectiva sociointeracionista. São Paulo: Plexus, 2003. 172 p.

NIENDICKER, C.; ZYCH, A. C. As interações do aluno surdo em sala de aula. Revista Eletrônica Lato Sensu. Paraná, Ano 3, n. 1, p. 1-11. Março de 2008. Disponível em: <http://web03.unicentro.br/especializacao/Revista_ Pos/P\%C3\%A1ginas/3\%20Edi\%C3\%A7\%C3\%A3o/Humanas/PDF/9-Ed3_ CH-InteracoesA.pdf> Acesso em: 18 abr. 2012.

PERLIN, G. T. T. O ser e o estar sendo surdos: alteridade, diferença e identidade. 2003. 156 f. (Curso de pós-graduação em Educação). Universidade Federal do Rio Grande do Sul. Porto Alegre, 2003. Disponível em: < http:// www.feneismg.org.br/doc/Ser\%20Surdos.pdf> Acesso em: 04 dez. 2011.

QUADROS, R. M.; KARNOPP, L. Língua de sinais brasileira: estudos linguísticos. Porto Alegre: Artmed. 2004, 139-156 p.

SILVA, D. N. H. Como brincam as crianças surdas. São Paulo: Plexus, 2002. $113 p$.

SKLIAR, C. A surdez: um olhar sobre as diferenças. 5. ed. Porto Alegre; Mediação. Porto Alegre. 2011. 190 p.

VIGOTSKI, L. S. A formação social da mente. 7. ed. São Paulo: Martins Fontes, 2007. $182 \mathrm{p}$.

\section{Notas}

${ }^{1}$ Segundo Bisol e Sperb (2010), a Educação de Surdos, com as iniciais em maiúsculo, significa reconhecer um grupo de pessoas com identidades compartilhadas que usam língua de sinais, sendo membros de uma minoria linguística e cultural, com valores e atitudes distintos. 
Carolina Oliveira Jimenez Silvestre - Erica Aparecida Garrutti de Lourenço

\section{Correspondência}

Érica Aparecida Garrutti de Lourenço - Universidade Federal de São Paulo, Estrada do Caminho Velho, 333, Pimentas, CEP: 07252-312 - Guarulhos, São Paulo, Brasil.

E-mail: carolinaojs@yahoo.com.br - egarrutti@yahoo.com.br

Recebido em 06 de agosto de 2012

Aprovado em 05 de novembro 2012 